\title{
Humanity Hypothesis Evolution at the Internet Age and Analysis on Its Corresponding Theories and Influences
}

\author{
Chen Liu \\ College of Business Administration \\ Northeastern University \\ Shenyang, Liaoning, China 110169
}

\author{
Xinbo Sun \\ College of Business Administration \\ Northeastern University \\ Shenyang, Liaoning, China 110169
}

\author{
Weixin Lin \\ College of Business Administration \\ Northeastern University \\ Shenyang, Liaoning, China 110169
}

\author{
Lanying Yao \\ College of Business Administration \\ Northeastern University \\ Shenyang, Liaoning, China 110169 \\ Jingwen Xia \\ College of Business Administration \\ Northeastern University \\ Shenyang, Liaoning, China 110169
}

\begin{abstract}
The development of management theories is in close relationship with development of humanity hypothesis and man's self-cognition greatly impacts development of management theories. "Learning man hypothesis" has a strong adaptability at Internet age, which makes it become a predominant one at this age. It is seen from the aspect of challenges encountered by traditional management theories under the Internet context that development trend of management theories has practical significance as well, while learning man hypothesis is closely connected with such development trend, and this paper aims to explore the relationship between them.
\end{abstract}

Keywords-humanity hypothesis; Internet age; learning man hypothesis

\section{INTRODUCTION}

Internet age is full of reform in high speed and the humanity hypothesis, under the management context based on industrial age and agricultural age, has not been adapted to needs of management science development at Internet age, so what kind of humanity hypothesis can be adopted into the management context becomes a very important issue. However, man's self-cognition cannot be decided by management context of one age only, and its development is relevant to predecessors' self-cognition. The development and evolution tracks of humanity hypothesis after 1980s reflect, in nature, change process of man's self-cognition under new management context. During over 30 years, there are more

Fund Program: program subsidized by National Undergraduate Training Program for Innovation and Entrepreneurship (program number: 150013), Duration: March 2015 to March 2016

[Chinese Library Classification] C93 [Document Code] A. than 10 kinds of humanity hypothesis coming to being, however, a majority of whose have a little influences due to their standpoints on the basis of management theories developed perfectly by predecessors rather than actual management context. With regard to the predominant humanity hypothesis at Internet age, it cannot be out of reality inevitably. Moreover, observing features of management activities at Internet age from the prospective in relation to development of humanity hypothesis is practically meaningful to development of management theories.

\section{ANALYSIS ON DEVELOPMENT TRAIN OF HUMANITY HYPOTHESIS AFTER 1980S}

Humanity hypothesis results from development of management science; although other subjects, including ethics, education and ecology, study humanity hypothesis to some certain extent, all of their natures are to realize management targets. Development of management theories experiences many stages, starting from traditionally classic management theories based on "economic man" hypothesis or even "tool man" hypothesis, then "cultural management theories" based on "cultural man" hypothesis, and to "knowledge management" and "information management" at Internet age. Development of humanity hypothesis theories always supplements and keeps in step with development of management theories.

\section{A. "Economy"-centered Humanity Hypothesis}

Economy at Internet age has strong externality and penetrability, and traditional industries still have wide markets 
at Internet age, which makes traditional humanity viewpoints still reasonable to some extent. The book "Multidimensional Game Humanity Hypothesis: Study on Cutting-edge Topics of Theoretical Management Science" published by GUO Xiangang in 2003 put forward with "multidimensional game man" hypothesis holding that management actors, subject to limited and reasonable bases, selected and gave up their own various needs with changing of management environment and maximized personal utility in the way of game with surrounding environment and other management actors [1]. Game man hypothesis is the new interpretation to "management man" hypothesis from a new prospective. The management strategy of "multidimensional game man" focuses on how to enable oneself to obtain maximum utility by means of one's behavior under different environment. In 2012, GE Rongjing with QIU Zhonglai put forward with "selfish man" in combination with Chinese ancient management thought. This hypothesis thinks humanity is selfish, so social relationships, in nature, belong to interest relationships and severe systems shall be taken to man for standardized management. [2]

\section{B. "Environment"-centered Humanity Hypothesis}

Classic management theories were developed by management science masters, like Taylor and Fayol. They provided theoretical guidelines for enterprises organizations at that time to coordinate labor-capital relationship and establish scientific management system for sake of production efficiency improvement. However, such management modes anxious to achieve quick success and instant benefit brought out serious disadvantages, and environmental damage was one of expressions in respect of such disadvantages. XU Songling, Chinese Scholar, put forward with "rationally ecological man" hypothesis in 1999, holding that man should pursue maximum economic profit as well as assume ecologically moral responsibility and obligation to life entities. [3] This hypothesis had a great influence and was generated with the background that economic development impacted adversely and greatly on environment. Thereafter, some other scholars put forward with some relevant humanity hypothesis, for example, "socially ecologic man" referring to man in compliance with ecologic development regulations as well as in harmonious co-existence and co-evolution with natural environment and social environment. [4] "Ecological man", put forward with by LI Zhonguan and YANG Maolin, rethought relationship between man and man, man and nature, as well as man and society, paid attention to harmonious coexistence between man and nature and realized systematicness, coordination and uniformity of ecology, economy and society from the viewpoint of man-society relationship. [5] Discussion by MENG Zhaowu on advantages/disadvantage and twosideness of "economic man", "moral man" and "ecologic man" hypothesis, criticized complete selfishness of "economic man", altruism of "moral man" and one-sideness of "ecological man". In the condition of harmonious socialist society, "harmonious man" is put forward with and realizes man in organic unity of economic rationality, moral rationality and ecological rationality. [6]

\section{C. "Culture"-centered Humanity Hypothesis}

Japanese enterprises achieved great success in 1980s. In respect of human resource management, Japanese enterprises at that time succeeded in applying permanent employment and annual salary system so as to let employees generate very strong sense of belonging, which attracted attention of management scholars around the world. Hereupon, "cultural management theories" came into being, which was jointly created by Professor Terrence Deal in Harvard University, USA and Management Consultant Allen Kennedy. Cultural theorist thought men were really not rational and effect of their emotional factors could not be ignored. In relation to management activities, not only logic or inference but also intuition and passion shall be considered. Man-centered management mode was put forward with by cultural theorists as well and held leading employees by values and humanistic care, paying attention to establish interpersonal relationship and releasing function of team spirit in enterprise management. It, in respect of incentive method, advocated participatory incentive to enhance employees' involvement and receptivity. Such a mode strengthened man's center position in management activities, and advocated man's nature full of rationality while weakened function of system in management activities. Target of management promotion was realized in more dependence of man's self-consciousness.

Japanese-American scholar William Ouchi published the book "Z Theory" in 1981 and in the book, he put forward with $\mathrm{Z}$ mode after contradiction between typical management modes of American enterprises and Japanese ones. The $\mathrm{Z}$ mode stressed great influence on development of employee by enterprise culture, which greatly promoted development of "cultural management theories". He also stressed that cultural values determined man's value, which had already been related to the core concept of "cultural man" hypothesis, but he did not clearly put forward with "cultural man" hypothesis. In 199, Professor LI Honglei in Sun Yet-Sen University put forward with "cultural man" hypothesis holding that man were cultural animals, and regarded advanced value culture as criterion as well as relyed on laborers' high subjectivity, selfconsciousness, uninterrupted study, continuous improvement and self-transcendence to keep prosperous vitality in the condition of knowledge economy. Russian theorist Peter Kropotkin was the first one to put forward with the concept of reciprocity. Afterwards, reciprocal economic theories came into being that was then introduced related studies of behavior science and game theory to develop "reciprocal man" hypothesis. "Reciprocal man" hypothesis could be opposite against "economic man" and stressed that man not only paid attention to ones' own benefit but also were likely to cooperate with surrounding people so as to maximize profit of individuals and organizations. [8] Management strategies of "reciprocal man" emphasized to establish proper performance assessment, award and punishment as well as daily standard regulations to promote members' reciprocity and to cultivate reciprocal enterprise culture so as to enhance members' organizational agreement sense. Based on "Essay on Man" by Cassirer, HU Rong and others in 2000 put forward with "virtual man" hypothesis holding spiritual attribute of man had been "virtualized" to a series of signals and man's cultural life and spiritual attribute could be deemed as various signals. [9] 
Management strategies in relation to "virtual man" hypothesis can be concluded into two points: firstly, due to signification and virtualization of such person-to-person relationship, management target, concept and method system will be changed revolutionarily, which can improve capability to catch person-to-person relationship; secondly, management activities are changed with change of man's time and space accordingly.

\section{D. "Knowledge"-centered Humanity Hypothesis}

From 1990s, with knowledge economy age coming, information and knowledge became important driving sources to promote economic development. Knowledge management became a research hotspot and many scholars defined knowledge management from many aspect. ZHONG Qiuyan, etc. defined knowledge management as "managing knowledge recourses within and out of organization by means related technology and methods, delivering knowledge to people in need at the first time, enhancing organizational capability to adapt to environmental dynamic changes, improving innovation capability and organization performance and keeping continuous competitive advantages." [10] During the course of humanity hypothesis development, hypothesis regarding "knowledge" as core to improve organizational innovation capacity and competitiveness exists as well.

In 1990s, Peter Senge put forward with the concept of learning organization and "learning man" hypothesis in his works "The Fifth Discipline" where he emphasized "changeable" parts of humanity and organization to overcome the unchangeable of "man" and "organization", and learning organization emphasized unity of man and organization as well as overall sense and unity sense of individual and organization. [11] Profession YU Wenzhao, based on theory of learning organization, specified connotation of "learning man" hypothesis, and self-transcendence, metal mode perfection, systematic thinking, common version and group learning were features of "learning man" hypothesis. Management strategies corresponded to by "learning man" hypothesis is more in common with "knowledge management" theories, which both emphasize knowledge sharing and pay attention to establish learning atmosphere. Knowledge is bounded with education inevitably, and in 1995, China put forward with strategy "developing the country through science and education" and attached importance to education and talent cultivation in the aspect of national strategy. Students' figurability as humanity hypothesis of education science by Johann Friedrich Herbart was referred to by WANG Jianhua as a previous case to put forward with "intellectual man" hypothesis in comprehensive consideration of particularity of profound knowledge in university. WANG Jianhua's, to some certain extent, covered dural features of "knowledge man" and "concept man". [12] In 2005, ZHANG Bingfu, in relation to educational reality, thought to study humanity from two aspects "initiative" and "existence" and then put forward to initiatively existent man hypothesis. [13] Besides, "wisdom man" hypothesis, "existent man" hypothesis, "quality man" hypothesis, etc. were important ones in China's educational field. In 2004, scholars including ZHANG Jun put forward with "knowledge man" hypothesis emphasizing man's "commonweal" and "rationality" at the time of pursuing economic profit, different from simply pursuing maximum economic profit by "economic man" hypothesis. [14] Management strategies of "knowledge man" advocate that human resource shall be regarded as the first resource of enterprise and importance of knowledge requires enterprise to conduct capitalized management to knowledge. In order to agree on capitalization, overall reform shall be implemented on traditional enterprise culture, property right system, corporate governance structure, etc. Reform stimulates concept generation and method improvement as well as advocates knowledge incentive to employees. Cultivating learning organization shall be treated as a long-term strategy of enterprises so as to facilitate knowledge innovation, transfer and sharing, which is in strong consistent with Drucker's viewpoint.

\section{ANALYSIS ON PREDOMINANT HUMANITY HYPOTHESIS AT INTERNET AGE}

\section{A. Analysis on Internet Ecology}

Ecology means ecologic status of life. In 1935, ecologist Tansly put forward with the concept of ecological system that within some certain time and natural space, life entities with environment formed a unified entirety and they were at a relatively stable dynamic balance state subject to mutual influence and restraint. [15]

Internet industry is open, dynamic, etc. [16], which is in consistent with mutual influence and restraint of ecological system, so concept of ecological system can be combined with Internet to generate Internet ecosystem consisting of every industry at Internet age. Logistic system, information publishing system, payment system, interaction system, etc. are key components in this system, while man is the center of this system. Internet ecosystem is an entirety and loss of any part will cause unbalance. It is seen from the prospective of industrial development, influence by Internet relates to all aspect, which includes promoting innovation and revolution of every industry and speeding up transformation and upgrading of every industry. Sale modes of agricultural products are changed greatly in the way of establishing e-commercial platform so as to promote upgrading and transformation of agriculture. In the industrial field, Internet has deeper influence: combination of Internet with industry promotes industrial digitalization and intellectualization; personalized customization becomes a trend; industry 4.0 age are walking towards us gradually. In service industry, including financial industry, mixing by Internet improves service quality and efficiency and decrease cost to promote upgrading of entire industry. [17] Man, as the center of management and Internet ecosystem, will be changed for adaption inevitably.

\section{B. Analysis on Humanity Hypothesis Development}

Humanity hypothesis both in management field as well as in educational and ecological fields aims to better guide and improve management activities. We can clearly include, after sorting out humanity hypothesis after 1980s, influence on development of humanity hypothesis theories by Internet ecodevelopment. At Internet age, humanity hypothesis development appears in various trends, which is determined by industrial structure at Internet age. Internet age does not mean 
elimination of traditional industries, but means development of traditional industries in contrast. In other words, development of various industries at Internet age results in diversity of humanity hypothesis development.

In order to better analyze humanity hypothesis, the author establishes humanity hypothesis determination module shown as "Fig. 1" consisting of four parts, Internet ecology, management context, man's adaptation and humanity hypothesis. This module is from conclusion and analysis of humanity hypothesis, and it is clearly seen from analysis on humanity hypothesis development that Internet ecology impacts greatly on humanity hypothesis development. Humanity hypothesis results from management science and management context directly impacts on humanity hypothesis development. Man's adaptation is in reference to natural selection theory by Darwin pointing out biological regulation "survival of the fittest in natural selection. Man is a kind of advanced creatures and shall comply with such a regulation. The author extends it to management field to analyze development regulations of humanity hypothesis and thinks that humanity hypothesis works and develops jointly on Internet ecology, management context and man's adaptation. But relationship among economic environment, management context and man's adaptation is not separated. Economic development and change impacts greatly on management context, and man's adaptation can be expressed under specific economic environment and management context.

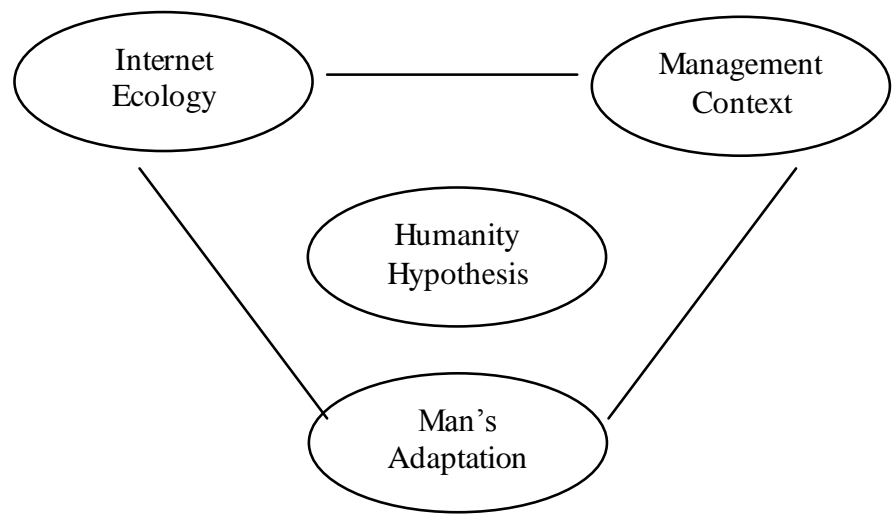

Fig. 1. Humanity hypothesis determination module

After reform and opening, China's economy is developed hugely and at the same time environmental issues become more and more visible. The influence on management context caused by environmental issues is that management needs to pay attention to environmental protection and target of management activities hence is changed to some certain extent. Man as principal part of economic development and management activities are supposed to adapt to such an objective environment naturally. China generates "rationally ecologic man" hypothesis, "socially ecologic man" hypothesis and "ecologic man" hypothesis in succession with this background. We, with the further informationization, meet Internet age. The importance of economic development is increased gradually. Knowledge competition, in nature, is talent competition. In 1995, China put forward with the strategy "develop the country through science and education". Therefore, education management was attached great importance to, and some people in education field, starting with methods and targets of talent cultivation, put forward with "quality man" hypothesis, "intellectual man" hypothesis, etc. But in management field, due to unbalance of economic development, there were relatively large differences on humanity hypothesis viewpoints put forwarded by every scholar based on different prospective, whereas their viewpoints still have reasonable aspects. Changes of economic environment and management context are continuous along with development of times. Humanity hypothesis can really guide management activities in the future must be in possession of obvious contingency character.

\section{Learning man-Predominant Humanity Hypothesis at Internet Age}

Development of management theories is on the premise of development of humanity hypothesis; entering into Internet age, great changes have been taken on political and economic environment as well as management context, so man has to adapt to such changes. In industrial society, industrial structure mainly includes labor-intensive and recourse-intensive and management target aims to improve production efficiency and production quantity meeting market needs, so "economic man" hypothesis is predominant hypothesis at industrial age. In correspondence to this, management theories, for example, $\mathrm{X}$ theory, put forward at Industrial age, possess such character. In contrast, at Internet age, economic development depends on knowledge increasingly, and business is globalized due to application of Internet and improvement of traffic tools; in addition, durability and efficiency of commercial activities is enhanced increasingly. So man's capability to accept new things and adapt to environmental changes is required increasingly.

Learning is man's instinct and a very important expression of man's adaptation. It results from experience to life and improves and develops oneself by means of life experience. It is seen from the aspect of information processing that learning is a process towards information input, feedback and output.

"Learning man" hypothesis starts from organization level, stresses learning of an entire organization and overcomes shortcomings of ones' characteristics and capabilities so as to enhance competitiveness of an entire organization. Such a humanity hypothesis is strongly in compliance with ecosystem at Internet age. As a result, "learning man" hypothesis is supposed to be predominant humanity hypothesis at Internet age.

\section{OBSERVING DEVELOPMENT TREND OF MANAGEMENT} THEORIES FROM THE ASPECT OF CHALLENGES ENCOUNTERED BY TRADITIONAL MANAGEMENT THEORIES AT INTERNET AGE

In the condition that Internet age is set as the main background, information between customers and enterprises is symmetrical and customers have a more influence on product development by enterprises. Some excellent management personnel have realized that current management context regards customers as centers rather than enterprises as centers 
and the trend of decentralization is increasingly obvious, which is quite different from traditional production methods.

With further development of Internet, there are some new organization formats coming to being, such as virtual organization, hollow organization, modularized organization, no-boundary organization, etc. Boundaries of organizations are unclear increasingly. Enterprises can start existence without boundaries in the way of Internet as medium. Information delivery and exchange across over levels and enterprises can be conducted by enterprises by means of mobile Internet tools. Meanwhile, Internet can be used as a tool by enterprises to absorb globalized capital as well as various resources for enterprise's development. Also the existence of internet decreases "transaction cost" in further step, which causes foundation of traditional enterprises' existence is decreased accordingly in further step, and Internet enterprises are blooming now. Whether traditional organization management theories can adapt to such a new environment becomes a big issue.

In order to express relationship between "learning man" hypothesis and management theories at Internet age, the author creates relationship module between "learning man" and management theories shown as "Fig. 2". Management theories at Internet age origin from transformation of traditional management theories, for example, "classic management theories", "cultural management theories", etc. And "learning man" hypothesis hereby plays an role of medium. Management context at Internet age directly determines tendency of "learning man" hypothesis. "Learning man" hypothesis and management theories at Internet age is not same as a simple and static process between "economic man" and management theories at Industrial age, but is a dynamic and variable process, which is strongly in consistent with economic changes in high speed at Internet age. It is seen from overall Internet ecosystem that learning view is an important driving factor for synergy and evolution of the whole social ecosystem, emphasized by "learning man" hypothesis.

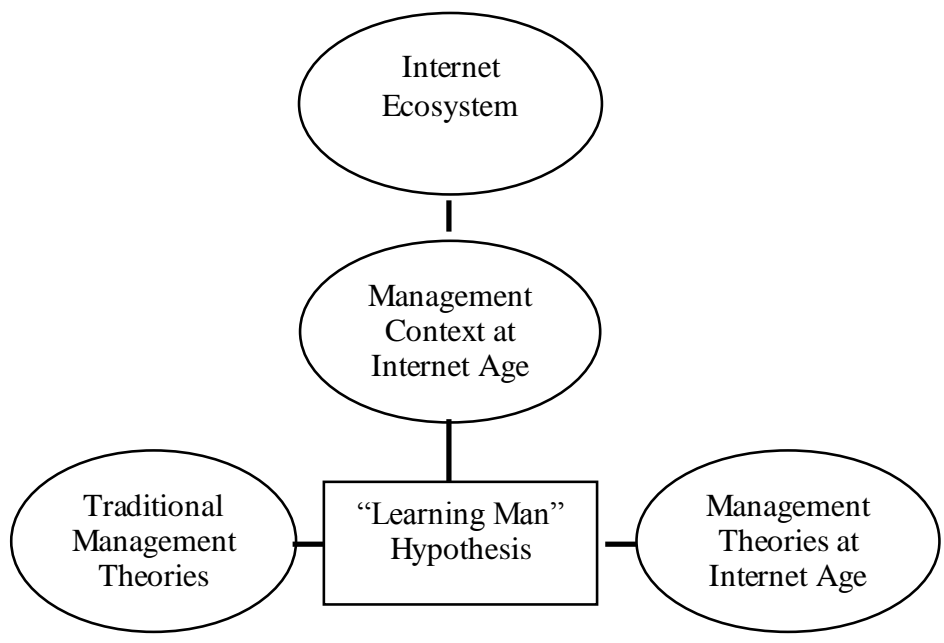

Fig. 2. Relationship module between "Learning Man" and management theories

Currently there are at stage of Internet economy being developing in high speed, and Peter Drucker points out that management is a kind of practice. Actions taken by enterprisers to confront challenges at Internet age can actually reflect the direction of management theories development. At present, more and more enterprises advocate flattening of organizational chart and pay attention to employees' innovation and learning capability. Management theories at Internet age, in this aspect, regard man as the center and stress man's development, which is more in common with "learning man" hypothesis. Learning organizations corresponded to by "learning man" hypothesis are relatively widely applied in real business communities, expressing "learning man" hypothesis well adaptive to Internet age. Management strategies corresponded to by "learning man" hypothesis develop "decentralization self-governance theory" held by Maslow so makes itself with obvious contingency character. With gradual in-depth of Internet in the future, "learning man" and its corresponding management theories will bring out more profound influence.

\section{CONCLUSION}

The core of management is management on man, so development of management science is along with development of humanity hypothesis. Management theories adaptive to Internet age needs support of humanity hypothesis inevitably; this paper, starting with development schools of humanity hypothesis and based on specific management contest at Internet age, analyses natures supposed to be possessed by humanity hypothesis at Internet age and obtains features of management theories at this age. Hopefully, it, to some extent, can be applied as reference for development of management theories at Internet age.

\section{REFERENCES}

[1] GUO Xiangang, "Multidimensional Game Humanity Hypothesis: Study on Cutting-edge Topics of Theoretical Management Science"[M], Guangdong Economic Press 2003, 2.

[2] GE Rongjing and QIU Zhonglai, "'Selfish' Humanity Theory and Standardized Management-Study on Hanfei Management Philosophy" [J], Journal of Beijing Administrative College, 2012,06:108-112.

[3] XU Songling, "Environmental Ethics Progress: Comment and Explanation" [M], Beijing: Social Sciences Academic Press, 1999, 419.

[4] ZHONG Zhenshan, HUANG Pinghuai and GE Gang, "Socially Ecologic Man: Man's Development Goal under Market Economy Condition" [J], Journal of Nanchang University (Humanities and Social Sciences Edition), 2006, 01:30-3.

[5] LI Zhongyuan and YANG Maolin, "Discussion on "Ecologic Man" Hypothesis and Its Economic, Social and Ecologic Significance" [J], Economic Problem, 2010, 07: 4-10.

[6] MENG Zhaowu and XIAO Yingsheng, "Harmonious Man: Criticism and Excess to Traditional Humanity Hypothesis" [J], Journal of Jishou University (Social Science Edition), 2012, 03: 8-13.

[7] LI Honglei, “'Cultural Man' Hypothesis and Its Management Concept-Management Philosophy in Knowledge Society" [J], Journal of Sun Yat-sen University (Social Science Edition), 1999, 06:96-101.

[8] Fehr, E. and S. Gachter [1998] "Reciprocity and Economics: The Economic Implications of Homo Reciprocans," European Economic Review 42, 845-59.

[9] HU Rong and WANG Fenghai, "Virtual Man” Hypothesis and Its management Philosophy" [J], Study on Financial and Economic Issues, 2003, 02: 19-23. 
[10] ZHONG Qiuyan, QU Gang, SONG Juan, MIN Qingfei, “Analysis and Connotation Definition on Features of Knowledge Management Schools" [J], Research and Development Management , 2010, 02: 80-88

[11] YU Wenzhao, "Revolution of Management: Theories and Methods to Create Learning Organization" [M], Shanghai Education Press, 2003

[12] WANG Jianhua, "Knowledge Man: A kind of Humanity Hypothesis of Higher Education" [J], University Education Science, 2009, 04:18 - 24

[13] ZHANG Bingfu, “'Initiatively Existent Man’: Logic Starting Point of Teaching Management" [J], Journal of Shanxi Police Academy, 2005, 04:54 - 58

[14] ZHANG Jun, ZHU Fangming and CHEN Jiansheng, "From 'Economic Man' to "Knowledge Man': Interpretation on Historical Transition of Humanity Hypothesis and Restructure of Economic Research Paradigm" [J], Economic Comment, 2004, 04:36 - 42

[15] Tansley A G. The use and abuse of vegetational concepts and terms. Ecology, 1935,16(3):284-307.P 299

[16] LIU Fang, "Analysis on Internet Industrial Features based on Ecological System Viewpoint" [J], Mechanical Industry Information and Network, 2008, 03:38-39

[17] LIU Bin, "Study on Current Development Situation of 'Internet+' and its Influence on China's Economy" [J], China's Collective Economy, $2015,24: 20-21$ 